\title{
The Use of Willingness to Pay Experiments: Estimating demand for piped water connections in Sri Lanka
}

\author{
Subhrendu K. Pattanayak, Caroline van den Berg, \\ Jui-Chen Yang, and George Van Houtven ${ }^{1}$
}

\begin{abstract}
This paper shows how Willingness to Pay surveys can be used to gauge household demand for improved network water and sanitation services when a private sector transaction is considered. We do this by presenting a casestudy from Sri Lanka, where we surveyed approximately 1,800 households in 2003. Using multivariate regression, we show that a complex combination of factors drives demand for service improvements. While poverty and costs are found to be key determinants of demand, we also find that location, self-provision, and perceptions matter as well, and that sub-sets of these factors matter differently for sub-samples of the population. To evaluate the policy implications of the demand analysis, we use the model to estimate uptake rates of improved service under various scenarios - demand in sub-groups, the institutional decision to rely on private sector provision, and various financial incentives targeted to the poor. The simulations show that in this particular environment in Sri Lanka, demand for piped water services is low, and that it is unlikely that under the present circumstances the goal of nearly universal piped water coverage is going to be achieved. Policy instruments, such as subsidization of connection fees, could be used to increase demand for piped water, but it is unclear whether the benefits of the use of such policies would outweigh the costs.
\end{abstract}

JEL classification: H4 Publicly Provided Goods; R2 Household Analysis; O1 Economic Development; O2 Development Planning and Policy

World Bank Policy Research Working Paper 3818, January 2006

The Policy Research Working Paper Series disseminates the findings of work in progress to encourage the exchange of ideas about development issues. An objective of the series is to get the findings out quickly, even if the presentations are less than fully polished. The papers carry the names of the authors and should be cited accordingly. The findings, interpretations, and conclusions expressed in this paper are entirely those of the authors. They do not necessarily represent the view of the World Bank, its Executive Directors, or the countries they represent. Policy Research Working Papers are available online at http://econ.worldbank.org.

\footnotetext{
1 Subhrendu K. Pattanayak is a Fellow, Environment, Health and Development Economics at RTI International (subrendu@rti.org) and Research Associate Professor at NC State University. Caroline van den Berg is a Senior Economist in the Energy and Water Department at the World Bank (cvandenberg@worldbank.org). Jui-Chen Yang (yang@rti.org) and George Van Houtven (gvh@rti.org) are Research Economist and Program Director in the Environment and Natural Resource Economics Program at RTI International. We have benefited from helpful discussions with Christine Poulos.
} 


\section{Introduction}

Irrespective of how one perceives the pros and cons of water sector reform, it is widely agreed that empirical evidence on household demand can generate critical inputs into water sector reform, including but not limited to the design of pro-poor contracts with public or private operators to deliver safe and reliable water to the public.

Because there is often no other pre-existing data on consumer demand for service quality improvements, the policy community usually relies on stated preference surveys (also called willingness-to-pay [WTP] surveys) to understand and estimate consumer demand. One potential problem from such surveys is that demand can be over-estimated because of the hypothetical nature of the survey. Such an error can trigger a spiral of activities leading to a negative impact on public and private investments in the water sector - i.e., lower than expected demand hurts the financial viability of water utilities, which results in insufficient revenues, which causes inadequate maintenance and poor service, which further lowers demand for service, and so on. We will argue that such over-estimates arise because of misinterpretation of concepts (e.g., WTP) and incomplete and inappropriate use of the data from such surveys.

We present a case-study from Sri Lanka, where we surveyed approximately 1,800 households in 2003 , to clarify concepts and offer an operational interpretation the use of WTP surveys to estimate coverage of piped water connections ex ante. In the early 2000s, the Government of Sri Lanka decided to engage private sector operators to manage water and sewerage services in two separate service areas: one in the town of Negombo, and one stretching along the coastal strip from the town of Kalutara to Galle. Since then, the government has abandoned the idea of setting up a public-private partnership in these two areas. This paper is part of a series of investigations to determine how pilot private sector transactions (forming part of the overall water sector reform strategy) could be designed in such a manner that they would benefit the poor.

What is the best way to estimate demand for a good or a service? The analyst usually will rely on people's revealed preferences (RP) for the commodity or service, using behavioral data to 
estimate parameters of demand and simulate coverage rate. Unfortunately, this approach will often not work for service such as improved supply of safe, reliable and sufficient water because there are no historical data in the context where the plans are being made. By definition, new government policies and improved products are beyond the range of historical experience. In this setting, the analyst typically has to rely on stated preference (SP) approaches such as contingent valuation surveys (also called WTP surveys) that directly elicit willingness (and ability) to pay statements from respondents (Mitchell and Carson, 1989). In other words, respondents are directly asked about their WTP (Whitehead et al., 2005). The method involves the development of a hypothetical market in the context of in-person, telephone, mail, or other types of surveys. In the hypothetical market respondents are informed about the current problem and the policy designed to mitigate the problem. The state of the environment before and after the policy is described. Other contextual details about the policy are provided such as the policy implementation rules (e.g., majority rule) and the payment vehicles (e.g., increased taxes or utility bills). Finally, a hypothetical question is presented that confronts respondents with a choice about improved environmental quality and increased costs versus the status quo. Respondents can be presented with multiple scenarios and make multiple choices.

In addition to solving the problem of missing 'behavioral data', consider two advantages of conducting WTP surveys in this context. First, seeking households' opinions and preferences during the planning and design stage is widely viewed as an important ingredient of the economic development process. Paraphrasing Sen (1998), participation is development. Second, the typical WTP survey presents an important form of experimentation which lies somewhere along the spectrum of laboratory experiments and observational studies. Such survey based 'field experiments' represent a practical mix of control and realism. Control comes from the design of the survey sample and the structure of the survey instrument. Contrasted to the laboratory settings of experimental economics, realism comes from interviewing people in their homes about goods and services that are important to their daily life, and considering the infrastructure programs that are familiar to respondents.

What can we get from WTP surveys for improved piped water services? It is important to review some of the qualifications regarding the typical product - mean WTP - because the economic concept measured by WTP can be difficult to grasp, leading to misinterpretations and misuses of results. Analysis and interpretation of survey data usually generates a measure of 
the maximum amount that the average survey respondent would be willing to pay for the proposed improvement in WSS in the context of the existing institutional regime within which households are free to allocate their financial resources. In the context of the case study presented here, WTP is the amount of monthly income that the average household could give up after obtaining the improved and or new WSS and be just as well off as in the situation without an improvement in water supply. By this token WTP is a measure of the average households' economic value and the basis for its preference for the proposed improvements in WSS.

Maximum WTP for the average household is related to but not equivalent to the future economic demand or to the monthly bill paid by households to the utility for new or improved WSS services. Although maximum WTP is related to both these concepts because it contains similar behavioral information about household preferences, it is different primarily because it is an ex ante measure of consumer surplus. From the perspective of estimating future demand, it does not tell us what level of the service (e.g., how much water) will be consumed. Instead, as a measure of consumer benefits, maximum WTP measures are best used in Kaldor-Hicks type social cost-benefit analysis - do the benefits of expanding piped water services exceed the costs of the infrastructure and operational investments?

In the remainder of this short paper, we show that in addition to generating a general measure of economic benefits, WTP surveys often produce two important pieces of operational information. First, because we usually implement a WTP study by using a split-sample survey experiment (different households are asked to consider different charges say for improved water services), we can trace out the demand in the service area that maps the relationship between charge and the number of people who will take up the service at that particular charge. Such an estimated relationship can depict the 'uptake rate' for the service improvements. This interpretation of WTP survey data is common in the health economics and finance literature (see Bala et al., 1999 for an early exposition).

Second, we often collect information on various characteristics of the households and the communities they live in - income, assets, education, attitudes, location, and amenities - that is typically under-utilized in interpreting and using WTP data. The heterogeneity that exists in the population may not be fully captured in the implementation of the randomized split-sample 
survey for at least two reasons. By pure chance we might end up with an imbalance in the distribution of user-charges such that, for example, poor households were consistently asked about high consumption charges in comparison to their rich counterparts. Moreover, usercharges (often the key design element in a WTP survey) may not be the only factor that impacts demand. Other 'demand shifters' such as connection costs, income, education, etc. are likely to matter. ${ }^{2}$ Some of these 'policy levers' such as connection costs and service quality can be evaluated through a more general class of SP surveys - conjoint experiments (see for example, Sills et al., [2004], Yang et al. [2005], and Mansfield et al. [forthcoming]). That still leaves a large residual heterogeneity. Our paper shows how regression modeling can be an important first step in accounting for, incorporating, and using this additional information on the population of interest.

In our analysis, the regression modeling shows that a complex combination of factors drives expressed demand for service improvements. While poverty and costs are found to be key determinants of demand, we also find that location, self-provision, and perceptions matter as well, and that sub-sets of these factors matter differently for sub-samples of the population. For example, these models suggest that poor households are more influenced by the proposed monthly consumption charge. We also find that perceptions, water quality, and safety nets affect poor households' WTP differently than non-poor. The regression models also show that all else equal, fewer households in the overall sample will connect to the network if this service improvement is provided by the private sector, in contrast to a reformed public sector.

The estimated coefficients from the regression modeling can also be used to further evaluate the uptake of piped water connections. In this paper, we use the model to evaluate the uptake of private piped water connections under various scenarios - demand in sub-groups, institutional decision to rely on private sector provision, and various financial incentives targeted to the poor.

2 In principle, you could construct a survey experiment that considers all the important features of demand. In reality, you would run into the curse of curse of dimensionality such that the individual cells will contain too few or zero observations to allow for reliable inference. Regression modeling gets around this curse by making some assumptions about the functional form of the model and the error. 
The remainder of this paper is organized as follows. In Section 2 we discuss how we can use data from field experiments such as WTP surveys to estimate uptake of piped water connections. Section 3 provides a brief overview of the data collection in Southwest Sri Lanka and a profile of our sample. Section 4 presents the quantitative findings from regression models of WTP. We then use the model to evaluate uptake of piped water (house) connections under various scenarios. Section 5 concludes.

\section{Gauging Demand for Improved Piped Water Service}

\section{General Framework for Demand Assessment}

WTP surveys can be used to gauge household demand for improved network water and sanitation services by presenting consumers with a contingent scenario in which they can obtain the described service. It is a technique originally and most widely used in the area of environmental economics to estimate the public's WTP for improvements in environmental quality (Cummings, Brookshire, and Shulze, 1986; Mitchell and Carson, 1989). Over the last decade, Contingent Valuation (CV) has been used increasingly in developing countries for improvements in WSS services. However, applying CV in developing countries requires careful adaptation of the method to account for local conditions and cultural differences (Whittington, 1998). Households can be asked to consider attributes of the service, including monthly usercharges and one-time connection costs, and to choose between scenarios that present different combinations of service levels, charges, and costs. WTP data from CV surveys measure the amount of monthly income that the household could give up after obtaining the improved network service and be just as well off as in a situation without an improvement in water supply or sanitation. Thus, it is a measure of the households' economic value. Maximum WTP and the survey response data define household values, underlie their demand for service improvements, and, therefore, inform tariff design.

Because of these features, WTP surveys represent a type of field experiment where the analyst balances control and relevance. The deliberate decisions employed in the framing of the survey 
questions, choice of the sample and the demand features such as user-charges and connection costs provides the 'control' that mimics an experiment. The 'sterility' of laboratories is replaced with field relevance by implementing the survey in the home environment of a typical user of the piped water service with questions that reflect service delivery programs that are both familiar to respondents and being considered by the service provider - the National Water Supply and Drainage Board (NWSDB).

The questions used in WTP survey can be either open-ended or closed-ended. In an openended question, the respondent is asked to state the monetary amount that he or she is willing to pay for the service that is being valued. With a closed-ended CV question (also referred to as a "dichotomous choice" or "referendum" question), the respondent is asked whether he or she is willing to pay a specified rupee amount for the good being valued. The respondent then answers yes or no. Open-ended questions, despite the fact that they provide more information than closed-ended questions, can be especially difficult for respondents to answer because individuals are typically not accustomed to performing such tasks in daily-life decision making. Therefore, we will use a closed-ended approach to elicit WTP for improved WSS services. Although easier for respondents to answer than open-ended questions, this type of question may not reveal the respondent's maximum WTP. The response to the closed-ended question provides a bound on the respondent's WTP, and the average WTP for respondents is estimated using a random utility modeling (RUM) framework and econometric models (Hanemann, 1984; Cameron and James, 1987; Cameron, 1988).

As stated above, we ask households to consider two scenarios: the improved service with certain quality and cost attributes, and the status quo. RUM model assumes the utility associated with a particular choice alternative is expressed as a function of individual characteristics and the attributes of the alternative, including costs. Under the assumptions of the RUM model, individual indirect utility is expressed as a function of WSS service attributes and personal characteristics: 


$$
U_{j t}^{i}=V^{i}\left(X_{j t}, Z^{i} ; \beta^{i}, \delta^{i}\right)+\varepsilon_{j t}^{i}
$$

where

$\mathrm{U}_{\mathrm{j} t}$ is individual $\mathrm{i}^{\prime} \mathrm{s}$ utility associated with each scenario, and $\mathrm{t}=1$ or 0

$\mathrm{V}^{\mathrm{i}}($.$) is the nonstochastic part of the utility function;$

$\mathrm{X}_{\mathrm{jt}}$ is a vector of attributes of the scenario such as user-charges and connection fees;

$\mathrm{Z}^{\mathrm{i}}$ is a vector of personal characteristics;

$\beta^{\mathrm{i}}$ is a vector of attribute parameters;

$\delta^{i}$ is the marginal utility of money; and

$\varepsilon \mathrm{i}_{\mathrm{jt}}$ is a disturbance term.

Stochastic utility maximization asserts that individual $\mathrm{i}$ will choose alternative $\mathrm{j}$ from among the full set of available alternatives $\mathrm{K}$ if, and only if, alternative j provides a higher overall level of utility than all other alternatives in the choice set. Thus, there decision to agree (yes =1) or refuse $($ no $=0$ ) can be estimated as simple dichotomous choice model, where the choice is a function of the utility difference between the preferred and rejected scenarios. ${ }^{3}$ This choice will reflect the respondent's willingness to pay for the service. Depending on our assumptions regarding the estimation error, we can estimate probit or logit models for parameteric estimates of WTP or Turnbull or Kaplan-Meir models to compute non-parameteric estimates of WTP.

\section{Empirical Strategy for Demand Estimation}

In general though, regression analyses of the current choice serves as a powerful tool to: (1) test joint hypotheses based on the statistical significance of the estimated coefficients, (2) estimate

\footnotetext{
${ }^{3}$ Mathematically, individual $\mathrm{i}$ will choose alternative $\mathrm{j}$ from among the set of alternatives $\mathrm{K}$, if Uijt > Uikt for all $\mathrm{j}$ in $\mathrm{K}, \mathrm{j} \neq \mathrm{k}$ substituting for Uijt from Eq. (1), and rearranging terms we have Vijt - Vikt > eikt eijt.
} 
the contribution of individual factors to the variable of concern, and (3) generate a function for out-of-sample predictions. For our study, each of these uses is relevant for identifying current choice to connect to the piped water network.

Consider a household's preferred choice of water and sanitation services. The following equation serves each of the three uses of multivariate regression described above:

$$
\Phi_{1}(\text { Choice })=\beta_{0}+\beta_{S} S+\beta_{C} C+\beta_{O} \mathrm{O}+\beta_{D} \mathrm{D}+\varepsilon_{1}
$$

where $\Phi 1$ is the probability distribution function, $\mathrm{Z}$ is a vector of economic factors, $\mathrm{X}$ is a vector of current water alternatives, $\mathrm{O}$ is a vector of opinion and attitudes, $\mathrm{D}$ is a vector of location characteristics, $\varepsilon 1$ is the regression error, and $\beta s$ are regression coefficients to be estimated. The list of variables included in these regression models should be based on intuition and practicality. While the primary criterion is the potential influence on household preferences, the choice is also conditioned by the availability of sufficient observations in the data set for the particular variable.

The dependent variable in this model is a binary variable taking on the value 0 or 1 . If we assume that the probability density of the variable $\Phi$ depends on the four factors $(X)$ described above and is normally distributed (see equation 2), we can estimate a multivariate probit regression. This model:

$$
\Phi\left(\beta^{\prime} \mathrm{x}\right)=\int_{-\infty}^{\beta^{\prime} x} \frac{\exp \left(-\mathrm{t}^{2} / 2\right)}{\sqrt{2 \pi}} \mathrm{dt}
$$

The statistical significance of the coefficients on these variables, for example, on the dummy variable indicating the very poor household shows that household choice is affected by poverty. The size of this coefficient tells us the magnitude of a unit change in the poverty measure on the probability of choosing a particular service. 
Because we vary the proposed consumption charge across the sample of households, the estimated coefficient on this variable allows us to estimate average WTP (Hanemann, 1984; Cameron, 1988; Cameron and James, 1987). The coefficients on the remaining variables essentially allow us to estimate how this WTP and the response varies by household characteristics. By including household characteristics, we can estimate the distribution of WTP by sub-groups such as regions, socio-economic status, and water use type. We also investigate differences between these sub-groups by using interaction terms. The results in Section 4.1 illustrate each of these uses of WTP data, including this first attempt to account for population heterogeneity.

Recall our motivation for an alternative operational use of the response to WTP surveys, relying on very simple logic. The use of a split sample survey design in which the type of provider in the WTP scenario is varied across the sample of households, the response data traces out a sample demand function for the improved piped water service. That is, for each proposed scenario we can derive the portion of the sample (or number of households) who will sign up (or are willing to pay) for the improved service (see Van Houtven et al. 2000; Cahn et al. 2004 for applications in the health field). We also know that the respondents come from different backgrounds and face different constraints. Moreover, some of these constraints can be relaxed through policy interventions such as subsidies (for use or connection) and information and education. When this data is used in a regression model, we can determine how this estimated sample demand curve "will shift" if those household characteristic and constraints change. This is the gist of the logic used to understand WTP data and employ it to simulate coverage rates of piped water connections for different groups and under different policy scenarios. Section 4.2 illustrates these uses of the WTP data. 


\section{Data Collection in Southwest Sri Lanka ${ }^{4}$}

\section{Study Design Summary}

The survey questionnaire was developed through a series of focus groups (in Kandy, Galle, and Kalutara regions of Sri Lanka); several purposive discussions with households and government officials (including staff from the National Water Supply and Drainage Board [NWSDB] and Water Sector Reform Unit in the Ministry of Housing and Plantation Infrastructure [WSRU]); and 120 pre-tests in Negombo, Kalutara and Peradeniya. The final survey comprised of various modules, including a split sample design on the contingent valuation to gauge household demand. Additional details on the insights from the focus groups, purposive interviews and pre-tests as well as the full text of the contingent valuation question are reported in Pattanayak et al. (2004).

These development stages led to the description of the service as providing: (1) 24-hour service with good pressure; 7 days a week, (2) prompt repairing and efficient customer service, (3) water that is safe to drink from the tap, and (4) meters that would function accurately and be read properly. Households who are currently connected to the piped water network were asked to consider increases in monthly consumption charges for a service that would provide 15 cubic meter of clean and safe water per month with the features described above. The monthly charge that was randomly distributed across the population sample ranged from Rs 100 to Rs 1,000. Households currently not connected to the network were asked to consider a new piped water service with identical features. In addition to monthly consumption charges for this service (which was distributed randomly from Rs. 100 to Rs. 1,000), they were also asked to consider a one-time connection cost (which varied from Rs. 6,000 to Rs. 12,000). To probe the institutional effect based on our focus groups findings that people were interested in the institution that would provide the service improvements, we split the sample of scenarios such

4 A more detailed description of the sample and survey design and survey implementation is reported in Pattanayak et al. 2004. 
that one half of our sample considered service provided by the private sector whereas the other half considered public sector provision. This assignment was random.

Enumerators were selected from a pool of recent Peradeniya graduates and trained using a combination of lectures, role-plays and field trials in the final survey area. Two field directors and three field coordinators supervised the implementation of the survey by 15 enumerators, divided into three 5-member teams including male and female interviewers. Negombo, Wadduwa, and Hikkaduwa served as the three staging areas for the survey.

We surveyed approximately 1,800 households from the two service areas (the town of Negombo, and the coastal strip from the towns of Kalutara to Galle) in order to be able to extrapolate our survey findings to the general population. The Water Sector Reform Unit in the Ministry of Housing and Plantation Infrastructure and the National Water Supply and Drainage Board defined the PSP service areas for us in terms of a list of 595 Grama Niladhari (GN) divisions, which stretched across 3 districts -Gampaha, Kalutara, and Galle-covering 17 Divisional Secretariat (DS) divisions.

A 3-stage stratified random sampling approach was used to select our sample. In stage 1, we determined the strata to be the GN division so that we would have sufficient geographical coverage and spatial representation of the PSP service area. In stage 2, we calculated the number of households we wanted to survey from each GN based on its population. To determine the number of households per GN, we calculated the ratio of each GN population to the total population in the PSP area multiplied by the total number of surveys we needed for each study area (800 surveys for the Greater Negombo and 1,000 for the Kalutara-Galle belt). In stage 3 we randomly picked the specified number of households from a pre-listing of households in every GN. The random selection of these households ensured that our sample was representative and allowed us to generalize our findings. 
We obtained household listings by GN from the Department of Census and Statistics (DCS).

The DCS maintains the Pre-Listing forms (also called F1 forms) for the 2001 Census of Population and Housing. These selected households constituted our survey sample and were contacted by our enumerators by using their names and addresses. We devised a geographical replacement rule for situations in which it was impossible to interview the selected household after repeat attempts. In addition to this rule, each enumerator was given a guideline document providing additional suggestions for using judgment to maintain the random sampling process.

Each survey was conducted as an in-person interview that lasted approximately 50 minutes. At the end of each field day, field coordinators checked the returned questionnaires for completeness and accuracy according to a quality checklist. During the field work, field directors periodically monitored interviews for quality purposes, ensured targeting of the appropriate population, discussed complications regarding the survey instrument with enumerators, recorded enumerator opinions regarding the quality of the interviews, maintained a list of sample household addresses for follow-up surveys and maintained a log of sample returned surveys. The survey process was completed in approximately 1,800 households over the course of 2 months.

Data recorded on the paper questionnaires were transferred into a statistical data set by an MS Excel program, which employed range, intra-record, and inter-record checks to ensure quality control. The identification of anomalies and outliers through the computation of descriptive statistics provided an additional quality control check.

\section{Sample Description}

Table 1 shows that the average family size is 4.8 members, with 1.3 children under 18 years of age. The typical (i.e., median) household head has 10 years of education. Over 90 percent of 
households have adults who have completed primary education and almost all households send their school-aged girls to school.

The typical household spends Rs. 21,615 per month, of which 38 percent is spent on food. About 60 percent of the households believe it is relatively easy to borrow money up to Rs. 5,000. The average household owns at least one of the following assets: gas oven, bicycle, radio, television, sewing machine, electric fan, and refrigerator.

Eighty-six percent live in single-story single-family houses that have cement floors, brick walls, and tiled roofs. The value of the median house is about Rs. 4,750 in terms of imputed monthly rent. The typical household indicated that their dwellings are located less than 250 meters from the piped water network, main road and bus stops. Figure 1 shows the location of households in and around the three towns of Negombo, Kalutara and Galle. We distinguish the households by poverty status (poor, non-poor) and water source type (private tap, well, neither) [Pattanayak et al., 2005a].

\section{Results and Findings}

\section{Descriptive statistics: What does the raw ('unconditional') data tell us?}

Figure 2 depicts the responses to the contingent service - 15 cubic meters of clean and safe water per month, 24 hours a day, 7 days a week, with regular and fair billing based on metered use, and prompt and efficient repairing and customer service - for the pooled sample of connected and unconnected households. It also shows the percentage of households who want such a service at different levels of monthly consumption charge. As shown in Figure 2 and predicted by economic theory, demand for the improved service is inversely related to its price - as the monthly consumption charge increases, the percentage of households willing and able to purchase the service declines. 
Based on this distribution, the median WTP for the improved service is about Rs. 200 for this pooled sample. Below we report how these estimates would be different for sub-groups such as the connected versus the unconnected or the poor versus the rich. Note, however, Rs. 200 is at least twice the amount that the typical household is currently paying and three times higher than the implied monthly charge. ${ }^{5}$

These results suggest that about 50 percent of the sample would sign up for the improved service at a consumption charge of Rs.200 a month, about 35 percent would sign at Rs. 500 a month, and only about 20 percent would sign up at Rs 800 a month. Thus, Figure 1 provides a rough picture of the uptake rate as a function of the monthly consumption charge. However, as discussed in the introduction, this is an incomplete picture because of to subscribe to the service households not only have to pay a monthly consumption charge but also a connection charge. The regression model presented in the next sub-section investigates these issues and provides the basis for computing piped water uptake rates for different sub-groups.

\section{Analytic statistics: Results of the regression analysis}

Following the logic presented in section 2.2, we use regression models to consider the influence of four broad categories of household characteristics on the demand for this service. First, we include economic variables such as whether the household is poor or not, the monthly consumption charge that the households will have to pay for improved or new service, and the connection cost for new services. Households who are currently connected to the piped water network will not have to pay the connection cost for the improved service levels (i.e., their connection cost is zero). Second, we consider the household's location and distances to the road. Third, we include substitutes for piped water such as whether the households in the neighborhood use private wells, and the numbers of other sources the household can access and

\footnotetext{
${ }^{5}$ Under the current tariff structure households would receive a bill of approximately Rs. 75 for 500 liters of water per day.
} 
use. Finally, we consider perceptions and factors influencing these perceptions, including the seriousness of the water pollution problem in their region, the seriousness of water supply problem, whether household members have suffered from diarrhea recently, and education level of the household head.

Results of the regression modeling are reported in Table 2. The reported model is the best among several models using different combinations of variables. The negative coefficient for the proposed monthly consumption charge confirms the downward sloping demand relationship. That is, at higher monthly bills, fewer households want the private connection. Moreover, the coefficient on the one-time connection cost is also negative as expected. All things considered, higher connection costs lower household demand for the improved services. Although the coefficient is small in size, the size of the variable is large enough to ensure that the product of the coefficient and the variable is large (see discussion below on measuring economic significance). As discussed in the uptake simulation below, the connection cost is the biggest constraint on demand, particularly among poor households, and offers a mechanism to change household demand.

The positive coefficient on per capita consumption confirms the finding of the previous section: poverty dampens demand and income-earning opportunities provide another mechanism to enhance demand for the improved service. We also find that households who receive remittances from abroad have a higher demand, presumably because it relaxes their income constraint. Households who receive payments from the Samurdhi program, the government's flagship welfare program, have lower demand. This may be a case of reverse causality - the program is targeted at poor households who are identified by their lack of a piped water connection and low ability to acquire one. Households who work in the private sector have a higher demand. 
Turning to location factors, we find that households farther from the road network have a significantly higher demand. We also see that households in the Greater Negombo and in Kalutara have a lower demand in comparison to those in Galle, after we control for socioeconomic status, substitutes, and perceptions.

Looking at substitutes to network connection, as expected households in neighborhoods with greater self-provision (primarily through private wells) have lower demand. This effect is amplified for households who like their non-network source. Those who rated their nonnetwork source as providing excellent or good quality water (measured in terms of taste, color, smell, safety, and regularity) have a significantly lower demand for water from network connections, and hence the probability that households which are satisfied with their current source will less likely connect to the piped network system making the governments' goal of (almost) universal piped water coverage more difficult to achieve.

When we consider other attitudes, households who believed that water contamination is the most important environmental problem have higher demand, presumably because the service improvement implies improved quality. Households who believe that the government should subsidize connections were not different in terms of their preferences from those who did not think the government should subsidize connections. Households who were particularly conscious of the health issues have a higher demand. That is, these households identified health consequences as the most important reason for choosing or rejecting the service improvements. Similarly, households who were focused on the institutional issues have a 
higher WTP. In other words, these households identified the institution as the most important reason for choosing or rejecting the service improvements. ${ }^{6}$

Our randomized splitting of the sample, such that one half of our sample considered service provided by a private operator whereas the other half considered service provision through a public operator, allowed us to investigate a key institutional issue. The assignment of a household to the private sector scenario is represented by a dummy variable. The negative coefficient on the private sector dummy shows that, all else equal, fewer households in the overall sample will connect to the network if this service improvement is provided by the private sector, in contrast to a reformed public sector. This is a singularly striking result - it represents the first formal test of a hypothesis that households tend to be biased towards private sector participation. Households tend to implicitly willing to pay a premium towards provision of water supply services through a public operator. As will be seen in the remainder of this section, the intensity of this bias varies across sub-samples of the population. The variation in the intensity will make it necessary for the government to follow different strategies to cope with this bias.

Looking at other household characteristics, we find that households who have experienced greater morbidity events have higher demand, again because the service improvements will decrease their morbidity cases. Tamil households have a lower demand, compared to other ethnic groups in the sample. House owners stated a lower demand compared to renters. All

${ }^{6}$ The health and institutional issues dummy variables are based on follow questions after the CV question. We asked households about their main reason for their saying yes or no to the CV question. Some said health, others said costs, and yet others said it was the type of institution that would provide the water. If they mentioned that the main reason was the institution, the institutional dummy variable for this household was set equal as 1 for these households and 0 for all others. If they mentioned that the main reason was health, the health dummy variable for this household was set equal as 1 for these households and 0 for all others. Even if these groups are small, our goal is to understand if those who were most concerned about the institution or about health were willing to pay more or less for the improved service. 
else equal, we find that more educated respondents have a greater demand and higher demand for the service improvements.

\section{Investigating heterogeneity: Regression with interaction terms}

We further investigate whether households who have connections, are poor and live in the Greater Negombo are significantly different from the overall sample by conducting additional regression analyses that include interaction terms. For this analysis, we sorted households into poor and non-poor categories based on their monthly per capita consumption, as described in Pattanayak et al. (2005a, 2005b). ${ }^{7}$ We then defined poor households as those households in the bottom two deciles, or the first quintile, of the distribution; we thus classify those households who spend less than or equal to Rs. 3,356 per capita per month as poor. While, poverty, connection status, and location are accounted for in the models described above, these additional regressions examine if these three sub-groups of households have different coefficients for each of the 21 variables included in Table 2. We do not, however, include all three interactions simultaneously because that would pose significant degrees of freedom problem, particularly for smaller combinations of sub-groups such as the poor, unconnected Greater Negombo residents. The overall purpose is to investigate heterogeneity in our sample. Coefficients on significant interaction terms should be added to the coefficient on the term by itself to see how the variable impacts demand for the sub-group in question.

${ }^{7}$ By this definition, 365 of our sample households are classified as poor, of which 124 live in the Greater Negombo and 241 live in the Kalutara-Galle strip. On the other end of the spectrum, households in the top quintile can be classified as rich. For this sample, households that spend more than Rs. 8,065 per month per person are classified as rich. By this definition, 362 sample households are classified as rich, of which 204 live in the Greater Negombo and 158 live in the Kalutara-Galle strip. This definition of the poor not only allows us to explore poverty relative to the overall socio-economic distribution, but also enables us to directly compare our results with other regions and countries if necessary 
The key findings for these models are reported in Table $3^{8}$. We start with households who are currently connected to the network and compare them to the unconnected households. The interaction coefficients are jointly significant suggesting some differences between connected and unconnected households. However, the significance of individual terms suggests that this difference is limited to only three substantive variables. First, compared to unconnected households, the demand for improved services by connected households is more sensitive to the size of the proposed monthly bill. This result is likely due to the fact that connected households have the option to stay at their current (lower quality) service level if they choose not to pay for the improved service. Another explanation may be linked to the fact that it is likely that connected households pay relatively more for service provision than unconnected households due to the widespread availability of relatively cheap alternative water supply sources. Second, belief that water pollution is the most important environmental problem does not significantly increase demand for improved services among connected households, presumably because of their perceptions of and experience with tap water quality (as households with piped water tend to be less satisfied with quality than households that depend on private wells). Finally, belief that government should provide subsidized connections tends to decrease demand for services among connected households.

Next we consider the sub-group of poor households and compare them to the non-poor households. That the interaction coefficients are jointly insignificant suggests there are only a few differences between the poor and non-poor. First, demand by poor households is more influenced by the proposed monthly bill, indicating a higher marginal utility of income (see Yang et al., 2005 for a similar finding). Second, experience with morbidity events does not significantly increase demand for services among poor households, possibly because they do not see a connection between the improved service and health. Third, a high rating for the quality of the non-network water among poor households does not lower their demand for

\footnotetext{
${ }^{8}$ For more details, on these models, see Appendix D (Tables D-3 through D-5) of Pattanayak et al. (2004).
} 
services, as it does for non-poor households with high ratings. Fourth, poor households who receive remittances have higher demand compared to similar non-poor households. This may point to the importance of safety nets in addressing the affordability concern. Finally, poor households who identified institutional issues to be the primary reason for their choice have a higher demand compared to similar non-poor households.

Finally we consider the sub-group of households who live in the Greater Negombo and compare them to the households living in the Kalutara-Galle coastal strip. The interaction coefficients are jointly significant, but only a subset of individual coefficients is significant. Starting with perhaps the most striking difference, compared to the coastal strip, Greater Negombo residents have a different preference with regard to the institutional status of the water supply service providers. Unlike households in the coastal strip, the demand for service improvements from households in Greater Negombo is higher when the improved services are provided by the private sector, all things considered. Second, Greater Negombo residents who live further from the road have a lower demand than similar households in the coastal strip. Third, Greater Negombo residents who rate the quality of non-network water sources (e.g., wells) highly have a lower demand than coastal strip residents. Finally, Greater Negombo residents who receive remittances have a lower demand.

\section{Simulating Coverage/Uptake Rates for Piped Water Connections}

The results reported in the previous sections present a complex reality of factors that drive household demand for network connections as expressed in their demand for service improvements. While poverty and costs are undoubtedly key determinants of demand, we find that location, self-provision, and perceptions matter as well, and that sub-sets of these factors matter differently for sub-samples of the population. The discussion till now has focused on statistical significance, which does not necessarily imply economic significance (McCloskey and 
Ziliak, 1996). Even if the p-values indicate that certain factors impact the WTP distribution, it does not tell us if the impacts are meaningful in economic terms.

In this concluding subsection, we investigate the economic significance of determinants of demand by conducting a simulation exercise. ${ }^{9}$ This simulation involves using the regression coefficients to predict the number of households who would connect to the improved service for different sub-groups and under different scenarios. The regression model and the relevant parameters used in these simulations was re-estimated by including the 11 statistically significant interaction terms discussed in the previous sections. The coefficients are reported in Table 3. Technically, we can interpret the output of the probit model, obtained as fraction between 0 and 1 , as the predicted percentage of a specified population who will connect under a specific scenario, where the scenario is created by inserting specified values for the independent variables. For example, if we want to specifically predict the connection rates for the poor who are already connected to services in Greater Negombo when the consumption charge is Rs. 200, then we set the poor household, Greater Negombo, and connected household dummy variable equal to one and the consumption charge variable equal to 200. The prediction simultaneously accounts for all other service, preferences, location, and socio-economic characteristics by similarly specifying their value and using the estimated regression coefficients. This is the essence of our uptake model. We consider three simulations.

For all the simulations reported and discussed below, we define 8 subgroups of the population. These subgroups are defined according to whether the households are poor or non-poor, connected or unconnected to services, and live in Greater Negombo or Kalutara-Galle. Table 4 reports the proportion of the overall study sample of 1818 that fall into each subgroup category. The largest subgroup, representing 28 percent of the sample, is the unconnected non-poor in

${ }^{9}$ The economic significance can be measured by multiplying the normalized coefficient for each variable by the household value of each of those variables. Each coefficient is normalized by dividing by the negative of the monthly bill coefficient to convert the utility values into money terms. 
Greater Negombo, and the smallest subgroup is the connected poor in Greater Negombo (just 2 percent).

We then define scenarios by varying the connection fee, the monthly charge, and whether the services are publicly or privately provided. To focus specifically on how these factors affect demand for services, we set all other independent variables at the mean of the total sample, as reported in Table 2. This approach to evaluating "partials" (e.g., impact of "private sector provision") by holding everything else constant is analogous to the Oaxaca decomposition method described in Ravallion and Wodon (1999).

The three sets of simulations are reported in Tables 5, 6, and 7. It is important to emphasize that all of these uptake predictions are for a service that does not currently exist in the PSP area - 15 cubic meters of clean and safe water per month, 24 hours a day, 7 days a week, with regular and fair billing based on metered use, and prompt and efficient repairing and customer service. Thus, the predicted rate should not be compared with current coverage to determine if we can increase coverage from current conditions. Instead, the purpose of these simulations is to compare predicted uptake rates under different service provision scenarios for different population subgroups.

In Table 5 we predict uptake rates for improved service that are specifically provided by the reformed public sector. For this simulation we assume that the all consumers have to pay a consumption charge of Rs 200 per month and the unconnected households have to pay a connection charge of Rs. 9,000 for a new connection. It is important to note that this specified monthly consumption charge is two to three times more than what households would pay for 500 liters of water per day under current tariffs and more than the current monthly bills for connected households. Based on these specifications, we predict the highest uptake rates for the connected non-poor in Kalutara-Galle (68 percent) and the lowest for the unconnected poor in 
Greater Negombo (30 percent). In general, we find that under these conditions uptake rates among connected households would be 17-18 percentage points higher than among unconnected households. Also, uptake rates for the non-poor would be 15-16 percentage points higher than for the poor, and uptake rates for those in Kalutara-Galle would be 5-6 percentage points higher than in Greater Negombo. This shows that the poor will less likely connect to the piped water system, and that system expansion will disproportionally benefit non-poor households.

In Table 6, we study the impact on uptake of the primary institutional factor under consideration - PSP or provision of improved service by the private sector. To do this, we set the private sector provision dummy equal to 1 in all of the predictions. We then combine this feature with the variable values used in the first simulation (Table 5), so that we can see if this uptake would be different among different sub-groups. As expected, we find a similar pattern of uptake rates across the 8 subgroups; however, the uptake rates with private provision are systematically lower than with public provision. For the subgroups and in Kalutara-Galle uptake rates are 8-9 percentage points lower. For Greater Negombo, the uptake rate show a more complex picture. Uptake rates in Greater Negombo are 1-2 percentage points higher with private provision. The differences in the bias are probably due to economic and cultural factors as Greater Negombo is more of an industrial zone than the coastal strip. Obviously, faced with such different biases between the two service areas, the government will have to use different communication and information strategies to deal with this bias and possibly use a different timetable by introducing private sector operators in the service areas to ensure that these biases can be rectified to ensure that the political viability of sector reform is not being jeopardized.

In Table 7, we conduct a set of financial simulations to investigate affordability constraints for the poor by using the connection cost and consumption charges as a direct policy levers under the reformed public sector. That is, we consider the impact on uptake if the poor are given connections free-of-charge and do not have to pay for the water they consume. This policy 
assumes that it is possible to find a type and form of targeting that is perfect (i.e., no errors of inclusion or exclusion). ${ }^{10}$ We look at each of these policies separately and jointly because there are strong advocates for one or the other approach. In this case, we find that uptake rates among the poor are all significantly higher. Compared to the results in Table 5 (with positive monthly charges and connection charges), the uptake rates increase by 19-20 percentage points for poor connected households and by 39-40 percentage points for poor unconnected households. Hence, large scale subsidization of the piped water service may have a positive impact on the poor gaining access to the service. Yet, despite the massive subsidization a still significant part of the poor population will still not be interested in making the switch from their current source to piped water, suggesting that subsidization can make a difference, but may not be sufficient to achieve universal coverage of piped water service.

\section{Discussion and Conclusions}

In this paper, we present a case-study from Sri Lanka, where we surveyed approximately 1,800 households in 2003, to clarify concepts and offer an operational interpretation of how WTP surveys can be used to estimate coverage of piped water connections. WTP surveys can be used to gauge household demand for improved network water and sanitation services by presenting consumers with a contingent scenario in which they can obtain the described service. These surveys are particularly useful as policy analysis tools because behavioral data are typically not available to estimate parameters of demand for service such as improved supply of safe, reliable and sufficient water. In addition to solving the problem of missing 'behavioral data', WTP surveys can contribute a valuable participatory element to the development planning process, and they provide an important type of 'field experiment' in which the analyst can mix control and realism in a practical way.

10 We investigate the options for targeting through geography and proxy means in a companion paper (Pattanayak et al., 2005). We conclude that while still imperfect, a mix of geographic and proxy means would be the most effective form of targeting for poverty reduction. These could be combined with several types of targeting, including placement of new pipelines (fundamentally geographic) and subsidized water connections and consumption (potentially based on proxy means). 
WTP surveys can certainly be used to generate a measure of the average households' economic value for the proposed improvements in WSS and to examine the factors that affect these values. However, we show that beyond a general measure of economic benefits, WTP surveys often produce two other important pieces of operational information. First, they can be used to obtain a demand curve that maps the relationship between charge and the number of households who will take up the service at that particular charge. Second, they can make productive use of often collected information on various characteristics of households and their communities- e.g., income, assets, education, attitudes, location, and amenities. We show how regression modeling can be an important first step for incorporating this additional information into demand analysis.

Field implementation in and around three towns of Southwestern Sri Lanka shows that urban households value improved water services. The median WTP is at least twice the amount that the typical household is currently paying and three times higher than the implied monthly water charge. There are important cautions and conclusions regarding use of WTP data. First, in the design of tariffs, WTP data should be complemented by supply-side information on costs and service area and by projected use levels (volumetric consumption and numbers of consumers). Second, they can be complemented by similar methods, such as conjoint analysis, to examine important dimensions of consumer preferences for service improvements other than price such as quantity, safety, and regularity (see Yang et al., 2005). Third, CV data are perhaps best viewed as a rough index of "genuine need" that can facilitate the design of subsidy policy. Fourth, the WTP data must be combined with a variety of socio-economic characteristics to develop a defensible and complete picture of need and affordability.

Multivariate regression modeling shows that a complex reality of factors drive household demand for network connections as expressed in their demand for service improvements. While poverty and costs are undoubtedly key determinants of demand, we find that location, access to alternative sources (in this case, mainly access to private wells), and perceptions 
matter as well, and that sub-sets of these factors matter differently for sub-samples of the population. For example, these models suggest that poor households are more sensitive to the level of the monthly consumption charge. We also find that health perceptions, water quality, perceptions on institutions and safety nets affect poor households' WTP differently than nonpoor. Overall we find that income constraints (measured specifically in terms of a household's poverty status) are a prominent underlying cause for low demand. The regression models also show that all else equal, fewer households in the overall sample will connect to the network if this service improvement is provided by the private sector, in contrast to a reformed public sector. Households tend to be willing to pay a premium towards provision of water supply services through a public operator. However, the analysis also showed that the intensity of this bias varies across sub-samples of the population, with an actual reversal for households in Greater Negombo whose uptake rates under private sector provision will be higher than under a scenario where services are provided through a reformed public sector operator.

We then use the model to evaluate uptake of private piped water connections under various scenarios - demand in sub-groups, institutional decision to rely on private sector provision, and various financial incentives targeted to the poor. Our simulation experiment also summarizes the policy implications of the demand assessment aspect of this study. Households who have low demand have some combination of the following features: they are not currently connected to the network, are poor, have a reliable system of self-provision, are satisfied with quality of existing water sources, are house owners, reside in Greater Negombo, and are less educated. Affordability is a prominent underlying cause for many of these factors, as shown by the simulation in which connections were given free-of-charge. Similarly, policies that indirectly address affordability, for example by increasing income and education levels of poor households and expanding the safety net, would increase uptake for all households in our sample. 
This simulation exercise has a normative goal of understanding the overall distribution of demand, explaining why some households have higher uptake than others, and considering policies for stimulating demand. Thus, there are at least two important caveats to using the statistics reported in Table 5 and 6 for tariff design. First, the regression analysis using 20 variables and aggregation of WTP into 12 estimates masks the statistical uncertainty surrounding each of these point estimates. For example, some of the sub-groups have less than 30 households. Second, these estimates are the outcome of a simulation experiment where we are constructing potential hypothetical scenarios. Comparisons of the predictions in Tables 5, 6, and 7 illustrate the impacts of various institutional, financial and locational decisions that could be made by the government. Thus, we must treat the predicted uptakes as indicative (and relative) and not precise and absolute. They are best used to understand the broad patterns of uptake.

It is worth re-iterating that lower rates of water-related diseases, lack of perceived links between water and personal health, reliable self-provision and overall satisfaction with existing sources play a big role in household demand for improved piped water services. If a greater number of households believed that drinking water was substantively contaminated or suffered from water-related morbidity, demand would be higher. Similarly, if fewer households were able to dig low-cost wells to provide for themselves or were not satisfied with the taste, color, or smell of existing sources, demand would be higher. The location of the project area in a disease free, relatively water abundant coastal zone with limited water quality problems clearly affects household needs and demands. Groundwater is available at easily accessible depths making it easy and cheap to build and maintain wells.

Collectively, the simulation analysis suggests that policy makers can employ a mix of connection subsidies and information, education and communication campaign to stimulate demand. Related research in South Asia show that demand and WTP are very sensitive to the option to finance a new connection through monthly payments added to the monthly 
consumption charge (Sills et al., 2004; Yang et al., 2003). Finally, this analysis shows that private connections to the piped water network are normal economic goods that are chosen by rational households who weigh the relative costs and benefits. Thus, overall economic growth, income redistribution or targeted poverty alleviation programs in the region will also enhance household demand for networked water services in the long run. In the interim, if inadequate access to and use of network water imposes significant social costs, governments could consider a variety of targeted subsidy policies to stimulate demand for piped water services. ${ }^{11}$ Yet, in view of the large subsidies needed to make (poor) households shift from their current source to piped water, it may be fiscally more prudent to postpone the proposed investments or shift the investments to other places or sectors in Sri Lanka, especially as the health impacts of piped water delivery tend to be small.

\footnotetext{
${ }^{11}$ In addition to geographic targeting that could address the location factors, the policy community could also consider income targeting (subsidized connections), consumption targeting (subsidized consumption) or self-targeting (subsidized public stand posts).
} 


\section{References}

Bala, M., J. Mauskopf, and L. Wood. 1999. Willingness to Pay as a Measure of Health Benefits. Pharmacoeconomics 15(1): 9-18.

Black, T.R. 1999. Doing Qualitative Research the Social Sciences: An Integrated Approach to Research Design, Measurement and Statistics. London: Sage.

Brocklehurst, C. 2002. "Setting the Stage: The Process of Preparing for Pro-poor Water Sector Reforms in Kathmandu." Field Note. Washington, DC: Water and Sanitation Program, the World Bank.

Cameron, T.A. 1988. "A New Paradigm for Valuing Nonmarket Goods Using Referendum Data: Maximum Likelihood Estimation by Censored Logistic Regression." Journal of Environmental Economics and Management 15:355-379.

Cameron, T.A., and M.D. James. 1987. "Efficient Estimation Methods for 'Closed-Ended' Contingent Valuation Surveys." Review of Economics and Statistics 69(2):269-276.

Canh, D.G., Dale Whittington, Le Thi Kim Thoa, Nugroho Utomo, Nguyen Thai Hoa, Christine Poulos, Dang Thi Dieu Thuy, Dohyeong Kim, Andrew Nyamet, and Camilo Acost. 2004.

"Household Demand for Typhoid Fever Vaccines in Hue, Vietnam: Implications for Immunization Programs". Unpublished Paper. RTI International.

Cummings, R.G., D.S. Brookshire, and W.D. Shulze. 1986. Valuing Environmental Goods. New Jersey: Rowman and Allanheld.

Estache, A., V. Foster, and Q. Wodon. 2002. Accounting for Poverty in Infrastructure Reform: Learning from Latin America's Experience. WBI Development Studies No 23950.

Hanemann, W.M. 1984. "Welfare Evaluations in Contingent Valuation Experiments with Discrete Responses." American Journal of Agricultural Economics 66(3):332-341. 
Mansfield, C., F.R. Johnson, and G. Van Houtven. forthcoming. The Missing Piece: Valuing Averting Behavior for Children's Ozone Exposures. Resource and Energy Economics.

Manski, C. 1977. The structure of random utility models. Theory and Decision 8: 229-254.

McCloskey, D., and S. Ziliak. 1996. “The Standard Error of Regressions". Journal of Economic Literature 34(1): 97-114.

McFadden, D. 1976. The Revealed Preferences of a Government Bureaucracy: Empirical Evidence. Bell Journal of Economics 7: 55-72.

Mitchell, R., and R. Carson. 1989. Using Surveys to Value Public Goods: The Contingent Valuation Method. Washington, DC: Resources for the Future, Inc.

Pattanayak, S.K., L. E. Carrasco, E. O. Sills, J.-C. Yang, C. van den Berg, C. Agarwal, and H. Gunatilake. 2005a. "The Economic Geography and Urban Water Supply: Evidence from Southwest Sri Lanka." RTI Working Paper.

Pattanayak, S.K., J.-C. Yang, K. Jones, H. Gunatilake, C. van den Berg, C. Agarwal, H. Bandara, and T. Ranasinghe. 2005b. "Poverty Dimensions of Water, Sanitation and Hygiene in Southwest Sri Lanka." RTI Working Paper.

Pattanayak, S.K., J.-C. Yang, D. Whittington, B. Kumar, G. Subedi, Y. Gurung, K. Adhikari, D. Shakya, L. Kunwar, and B. Mahabuhang. 2001. Willingness to Pay for Improved Water Services in Kathmandu Valley. Submitted to the World Bank, Water and Sanitation Program, August.

Pattanayak, S.K., J.-C. Yang, C. Agarwal, H.M. Gunatilake, H. Bandara, and T. Ranasinghe. 2004. Water, Sanitation and Poverty in Southwest Sri Lanka. Submitted to the World Bank, Water and Sanitation Program, March. 
Ravallion, M. and Q. Wodon, 1999. Poor areas, or only poor people? Journal of Regional Science 39(4): 689-711.

Sen, A., 1998. Development as Freedom.

Sills, E.O., S.K. Pattanayak, and D. Whittington. 2004. "Water supply coverage and cost recovery in Kathmandu: Understanding the role of time preferences and credit constraints." RTI Working Paper.

The Economist. 2003. “Bogged Down." March 22nd print edition.

Van Houtven, G., S.K. Pattanayak, A. Richter, D. Whittington, J. Freiberger, K. Komives, A. de Nazelle, and O. Matsui-Santana. 2000. “The Willingness to Pay and Demand for Triple Drug Therapy in Mexico." Report submitted to Glaxo-Smith Kline. RTI International.

Whitehead, J., S. K. Pattanayak, G. L. Van Houtven, and B. Gelso. 2003. “Combining Revealed and Stated Preference Data to Estimate the Nonmarket Value of Ecological Services: An Assessment of the State of the Science." RTI Working Paper.

Whittington, D. 1998. “Administering Contingent Valuation Surveys in Developing Countries." World Development 26(1):21-30.

World Bank. 2004. Drinking water, sanitation, and electricity. World Development Report.

Yang, J.-C., S.K. Pattanayak, and V. Foster. 2003. “Inequality Subsidized? Distributional Incidence of Water Sector Tariffs in Kathmandu, Nepal." Discussion Paper 03_05. Research Triangle Park, NC: RTI International.

Yang, J-C, S.K. Pattanayak, F.R. Johnson, C. Mansfield, K.M. Jones, and C. van den Berg. 2005. “Un-packaging Demand for Urban Water Supply: Evidence from Conjoint Surveys in Sri Lanka". RTI Working Paper. 


\section{Acknowledgements}

The authors would like to acknowledge the contributions of H. Gunatilake, C. Agarwal, H. Bandara, T. Ranasinghe, G.G. Jayasinghe and all 13 field enumerators, including S.M. Chandrakanthi, Erandathi Jayasinghe, Lalith Sudusinghe, Madhupani Samaratunge, Preethi Thushari Kulatunga, Sandhya Wickramaratne, Suranga Jayasundara, Kapila Abayasinghe, Suminali Gunatilake, Champika Roshan, Lalani Darmamala Ranawake, Chalani Indika Attanayake, and Thusitha Gunarathna in the data collection. The authors are grateful to Clarissa Brocklehurst (lead consultant) for her guidance regarding all aspects of this study; and Cate Corey for her help with the literature review, design of health modules, and proof-reading. Finally, we would like to thank Chandra Perera (WSRU), Shanta Fernando (NWSDB), U. Ratnapala (WSRU), Chrishan Fernando (NWSDB) and Rizwan (NWSDB) for their help during the design and implementation phases of this study. Financial support from the BankNetherlands Water Partnership for Water Supply and Sanitation (BNWP-WSS), a facility that enhances World Bank operations to increase delivery of water supply and sanitation services to the poor, is gratefully acknowledged. The opinions reflected in this paper do not represent the opinions of the World Bank, RTI International, or the BNWP-WSS. 
Figure 1. Household locations, Poverty Status and Type of Water Sources

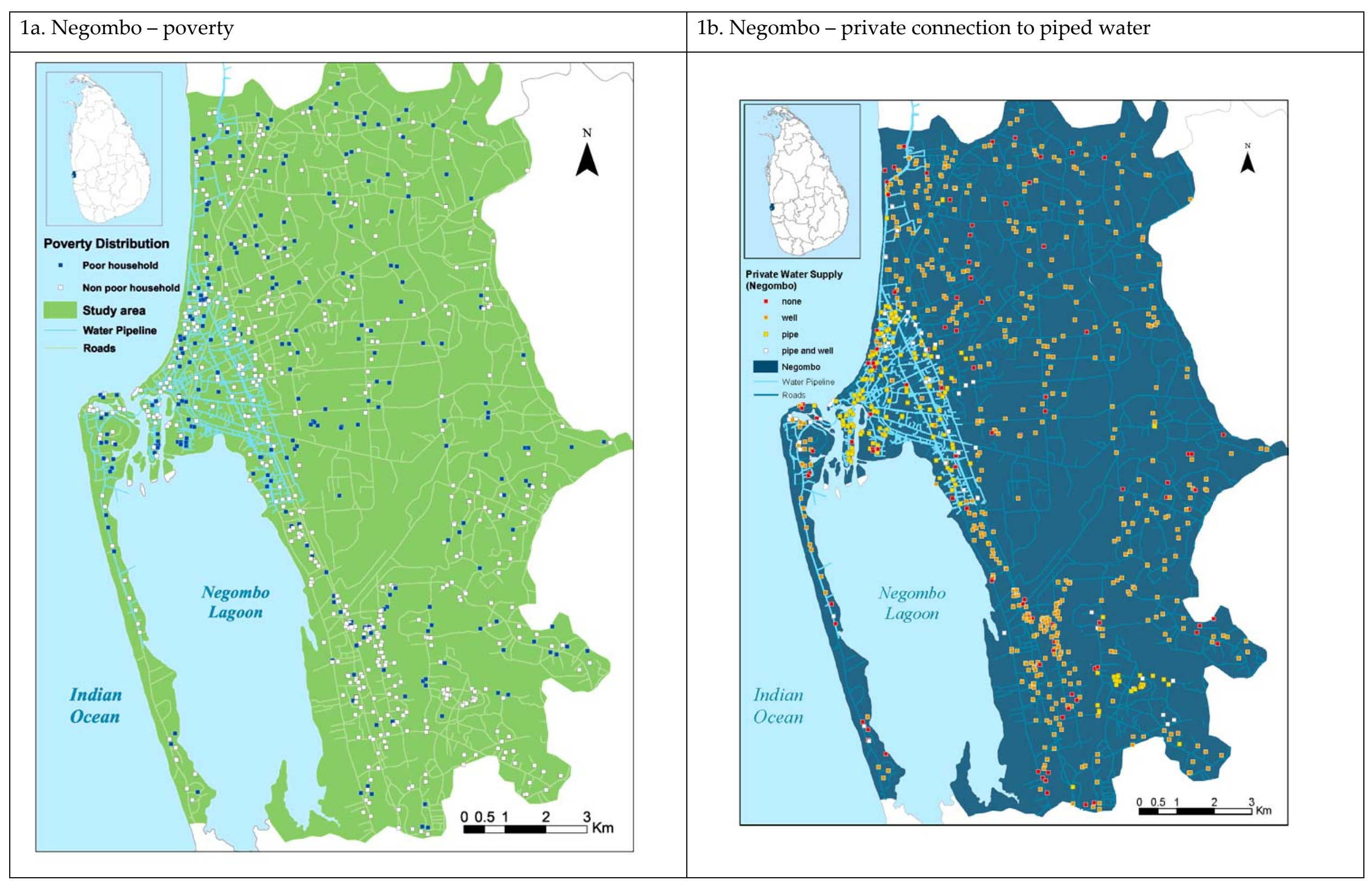




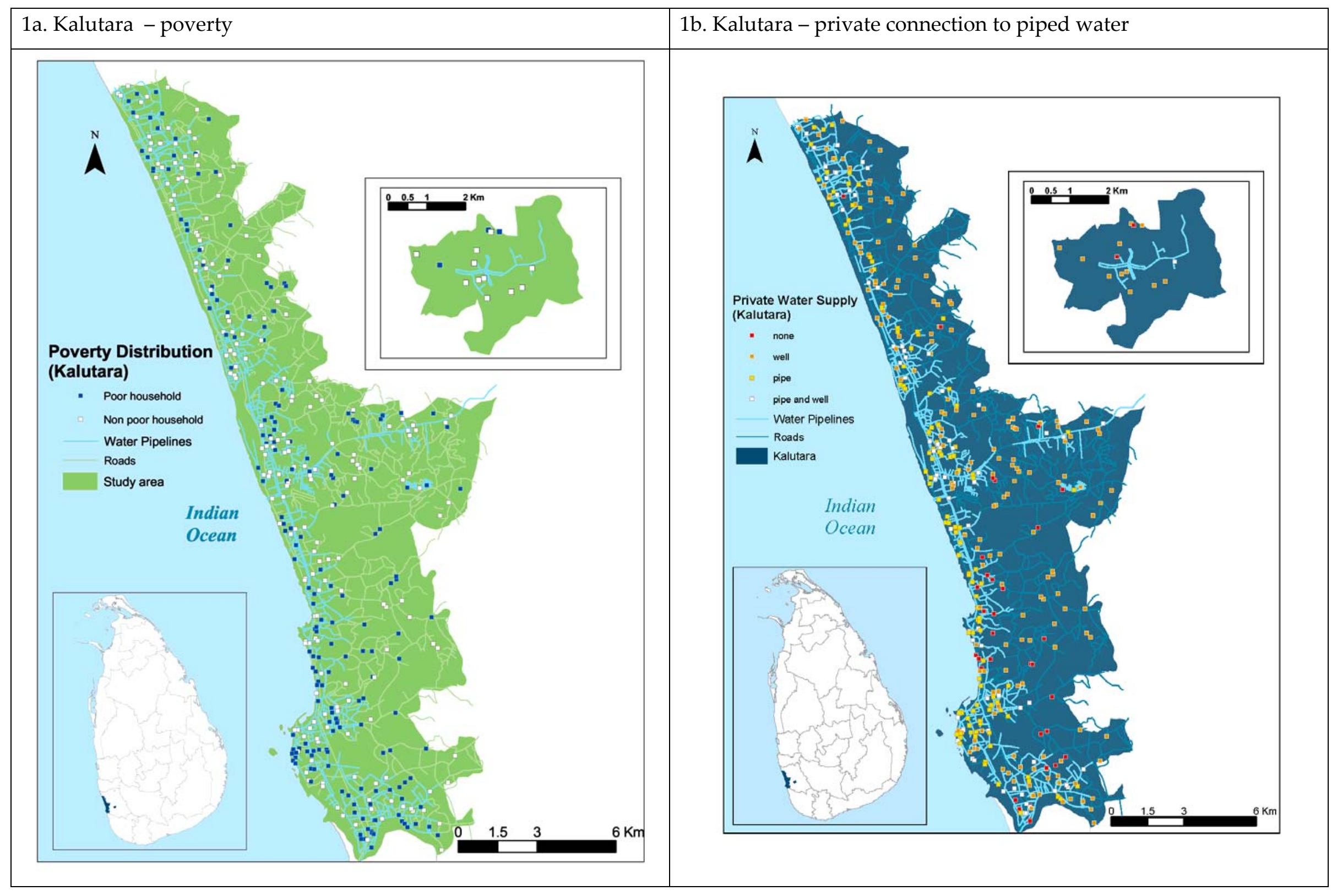




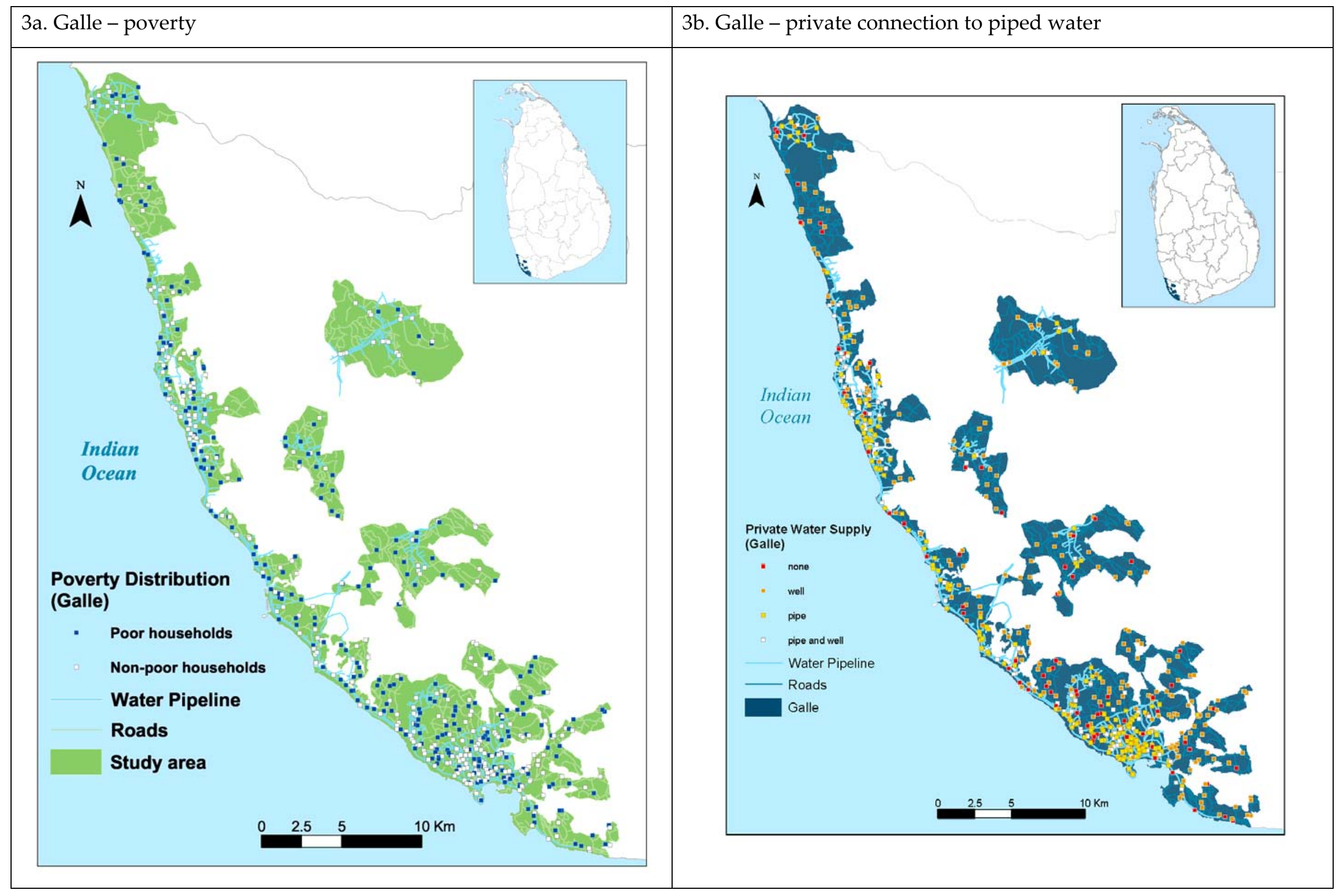


Figure 2. Demand Curve for Improved Service Based on Sample Statistics.

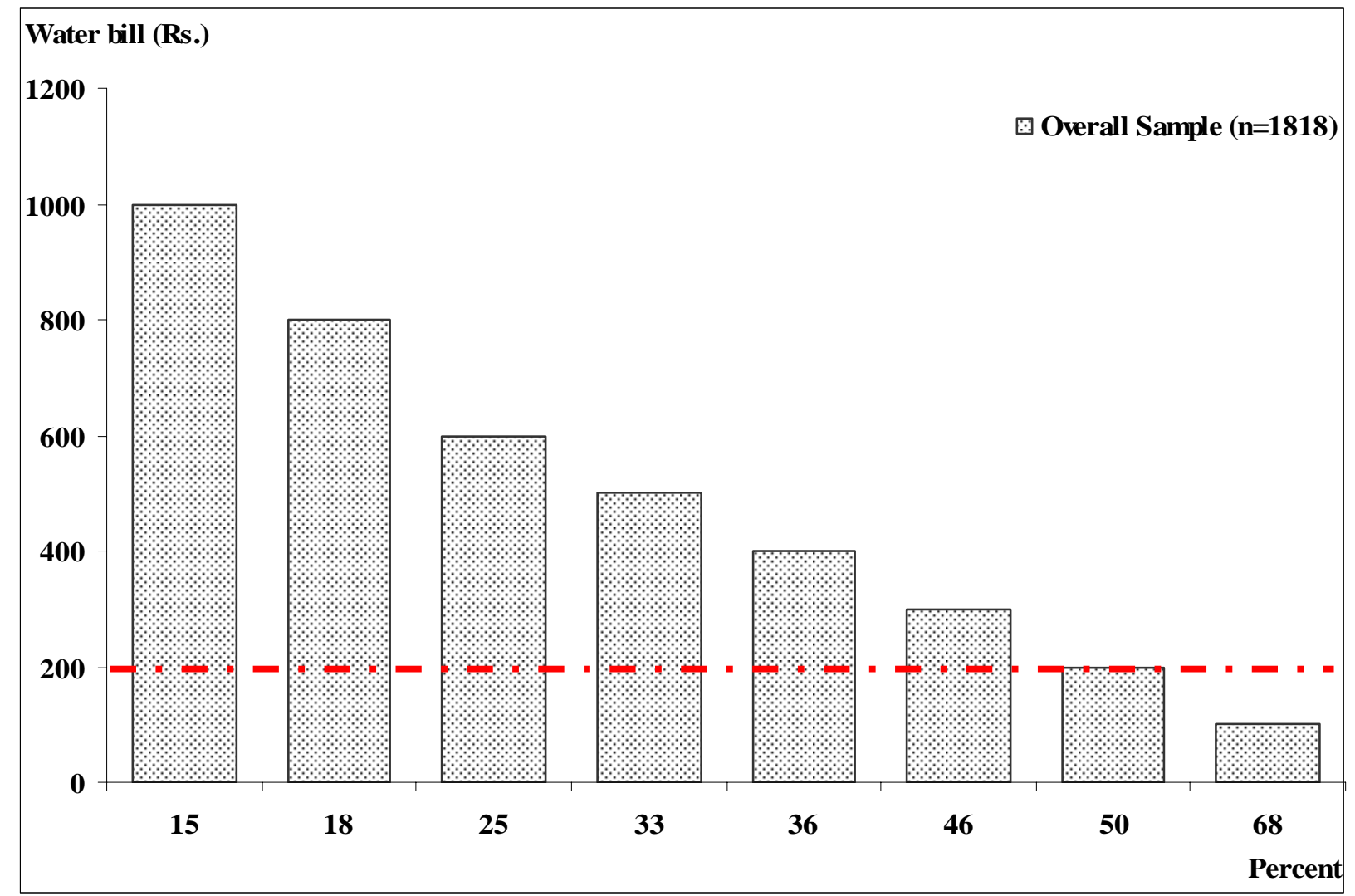


Table 1. Demographics and Socioeconomics*

\begin{tabular}{|c|c|}
\hline Demographics and Socioeconomics & $\begin{array}{r}\text { Overall } \\
(\mathrm{n}=1818)\end{array}$ \\
\hline$\%$ Sinhalese & 89 \\
\hline$\%$ Buddhist & 62 \\
\hline Family size & 4.8 \\
\hline Adult equivalent & 3.5 \\
\hline$\%$ have children under 5 & 26 \\
\hline Household head's education attainment (years) & 10 \\
\hline$\%$ have adults who have completed primary school & 93 \\
\hline$\%$ have girls attending school & 99 \\
\hline Monthly consumption (Rs.) & 21,615 \\
\hline Monthly per capita consumption (Rs.) & 5,294 \\
\hline$\%$ Food expenditure & 38 \\
\hline Monthly per capita food expenditure (Rs.) & 1,953 \\
\hline$\%$ living on less than US\$ 1 a day & 13 \\
\hline \multicolumn{2}{|l|}{ Primary occupation } \\
\hline Government & 22 \\
\hline Business & 17 \\
\hline Private sector & 16 \\
\hline Manual labor & 11 \\
\hline$\%$ received Samurdhi & 19 \\
\hline \% can borrow Rs. 3,000-5,000 relatively easily & 58 \\
\hline \multicolumn{2}{|l|}{ Housing conditions } \\
\hline$\%$ single family and singe story & 86 \\
\hline$\%$ have cement floor & 92 \\
\hline$\%$ have red brick/cement walls & 94 \\
\hline$\%$ have tiled roof & 76 \\
\hline Amortized monthly housing rent (Rs.) & 4,744 \\
\hline \multicolumn{2}{|l|}{ Distance to infrastructure } \\
\hline Piped water network (kilometers) ${ }^{* *}$ & 0.2 \\
\hline Main road (kilometers) & 0.1 \\
\hline
\end{tabular}


*All statistics are presented in either the percentage term or the median value.

** This 'median' statistic masks the fact that distance to the network essentially falls into three broad classes: 52 percent of the dwellings which are less than 250 meters from network; 17 percent which are less than 1000 meters from the network; and 31percent which are greater than one kilometer from the network and as much as 15 kilometers from the network. Thus, the median is 0.25 kilometers, whereas the mean is about 3.25 kilometers. 
Table 2. How Household Characteristics impact Demand for Improved Piped Water Service - Probit Regression

\begin{tabular}{|c|c|c|c|}
\hline Variable & Mean & Coefficient & p-value \\
\hline Regression Constant & 1.00 & 1.357 & 0.000 \\
\hline Monthly consumption charge (Rs.) & 487 & -0.002 & 0.000 \\
\hline One time connection fee (Rs.) & 5534 & -0.00003 & 0.007 \\
\hline Household is poor $(1=$ yes; $0=$ no $)$ & 0.20 & -0.309 & 0.002 \\
\hline Household receives remittance $(1=$ yes; $0=$ no $)$ & 0.10 & 0.288 & 0.009 \\
\hline $\begin{array}{l}\text { Household is a Samurdhi recipient }(1=\text { yes; } 0= \\
\text { no) }\end{array}$ & 0.19 & -0.224 & 0.023 \\
\hline $\begin{array}{l}\text { Household head is employed in private sector }(1 \\
=\text { yes; } 0=\text { no) }\end{array}$ & 0.41 & 0.200 & 0.004 \\
\hline Distance to main road (kilometers) & 0.32 & 0.113 & 0.131 \\
\hline $\begin{array}{l}\text { Household resides in Negombo }(1=\text { yes; } 0= \\
\text { Kalutara or Galle) }\end{array}$ & 0.45 & -0.479 & 0.000 \\
\hline $\begin{array}{l}\text { Household resides in Kalutara }(1=\text { yes; } 0= \\
\text { Negombo or Galle })\end{array}$ & 0.23 & -0.318 & 0.001 \\
\hline$\%$ households have access to private well in GN & 0.79 & -0.316 & 0.019 \\
\hline $\begin{array}{l}\% \text { households think water quality of their } \\
\text { alternative sources is excellent or good in GN }\end{array}$ & 0.59 & -0.325 & 0.010 \\
\hline $\begin{array}{l}\text { Household believes that there is a water } \\
\text { contamination problem }(1=\text { yes; } 0=\text { no })\end{array}$ & 0.10 & 0.243 & 0.026 \\
\hline $\begin{array}{l}\text { Household thinks government should give } \\
\text { connection subsidy to low-income households } \\
\text { for improved water supply services ( } 1 \text { = yes; } 0= \\
\text { no) }\end{array}$ & 0.30 & 0.024 & 0.743 \\
\hline $\begin{array}{l}\text { Household is particularly conscious of } \\
\text { institutional issues }(1=\text { yes; } 0=\text { no })\end{array}$ & 0.01 & 0.609 & 0.028 \\
\hline $\begin{array}{l}\text { Private sector will provide improved service }(1= \\
\text { yes; } 0=\text { public sector will provide) }\end{array}$ & 0.55 & -0.121 & 0.074 \\
\hline $\begin{array}{l}\text { Household is particularly conscious of health } \\
\text { issues }(1=\text { yes; } 0=\text { no })\end{array}$ & 0.02 & 0.649 & 0.003 \\
\hline $\begin{array}{l}\text { Household has experienced a case of morbidity } \\
\text { event }(1=\text { yes; } 0=\text { no })\end{array}$ & 0.02 & 0.653 & 0.006 \\
\hline Household is Tamil $(1=$ yes; $0=$ no $)$ & 0.03 & -0.475 & 0.047 \\
\hline Household owns the house $(1=$ yes; $0=$ no $)$ & 0.94 & -0.352 & 0.015 \\
\hline
\end{tabular}




\begin{tabular}{|l|c|c|c|}
\hline Variable & Mean & Coefficient & p-value \\
\hline Education of household head (years) & 8.94 & 0.022 & 0.065 \\
\hline Number of observations & & 1735 & \\
\hline Likelihood Ratio Statistic $\chi^{2}(20)$ & & 390 & 0.000 \\
\hline Pseudo R & & 0.17 & \\
\hline$\%$ Responses that are correctly predicted & & 73 & \\
\hline Log likelihood & & -942 & \\
\hline
\end{tabular}


Table 3. How Household Characteristics Impact Demand for Improved Piped Water Services - Probit Regression with Selected Interacted Terms

\begin{tabular}{|c|c|c|c|}
\hline Variable & Mean & $\begin{array}{c}\text { Coefficie } \\
\text { nt }\end{array}$ & p-value \\
\hline Regression Constant & 1.00 & 1.443 & 0.000 \\
\hline Monthly consumption charge (Rs.) & 487 & -0.001 & 0.000 \\
\hline One time connection fee (Rs.) & 5534 & -0.00007 & 0.000 \\
\hline Household is poor $(1=$ yes; $0=$ no $)$ & 0.20 & -0.31564 & 0.207 \\
\hline Household receives remittance $(1=$ yes; $0=$ no $)$ & 0.10 & 0.299 & 0.071 \\
\hline Household is a Samurdhi recipient $(1=$ yes; $0=$ no $)$ & 0.19 & -0.211 & 0.036 \\
\hline $\begin{array}{l}\text { Household head is employed in private sector }(1= \\
\text { yes; } 0=\text { no) }\end{array}$ & 0.41 & 0.205 & 0.004 \\
\hline Distance to main road (kilometers) & 0.32 & 0.217 & 0.048 \\
\hline $\begin{array}{l}\text { Household resides in Negombo }(1=\text { yes; } 0=\text { Kalutara } \\
\text { or Galle) }\end{array}$ & 0.45 & -0.335 & 0.053 \\
\hline $\begin{array}{l}\text { Household resides in Kalutara }(1=\text { yes; } 0=\text { Negombo } \\
\text { or Galle) }\end{array}$ & 0.23 & -0.333 & 0.000 \\
\hline$\%$ households have access to private well in GN & 0.79 & -0.232 & 0.098 \\
\hline $\begin{array}{l}\text { \% households think water quality of their alternative } \\
\text { sources is excellent or good in GN }\end{array}$ & 0.59 & -0.381 & 0.012 \\
\hline $\begin{array}{l}\text { Household believes that there is a water } \\
\text { contamination problem }(1=\text { yes; } 0=\text { no })\end{array}$ & 0.10 & 0.422 & 0.002 \\
\hline $\begin{array}{l}\text { Household thinks government should give } \\
\text { connection subsidy to low-income households for } \\
\text { improved water supply services }(1=\text { yes; } 0=\text { no) }\end{array}$ & 0.30 & 0.143 & 0.137 \\
\hline $\begin{array}{l}\text { Household is particularly conscious of institutional } \\
\text { issues }(1=\text { yes; } 0=\text { no })\end{array}$ & 0.01 & 0.273 & 0.437 \\
\hline $\begin{array}{l}\text { Private sector will provide improved service }(1=\text { yes; } \\
0=\text { public sector will provide) }\end{array}$ & 0.55 & -0.228 & 0.012 \\
\hline $\begin{array}{l}\text { Household is particularly conscious of health issues ( } 1 \\
=\text { yes; } 0=\text { no) }\end{array}$ & 0.02 & 0.654 & 0.003 \\
\hline $\begin{array}{l}\text { Household has experienced a case of morbidity event } \\
(1=\text { yes; } 0=\text { no })\end{array}$ & 0.02 & 0.985 & 0.001 \\
\hline Household is Tamil $(1=$ yes; $0=$ no $)$ & 0.03 & -0.529 & 0.035 \\
\hline
\end{tabular}




\begin{tabular}{|c|c|c|c|}
\hline Variable & Mean & $\begin{array}{c}\text { Coefficie } \\
\text { nt }\end{array}$ & p-value \\
\hline Household owns the house $(1=$ yes; $0=$ no $)$ & 0.94 & -0.359 & 0.015 \\
\hline Education of household head (years) & 8.94 & 0.032 & 0.009 \\
\hline CONNECTED*Monthly consumption charge & 185 & -0.001 & 0.013 \\
\hline $\begin{array}{l}\text { CONNECTED*Household believes that there is a } \\
\text { water pollution problem }\end{array}$ & 0.03 & -0.567 & 0.020 \\
\hline $\begin{array}{l}\text { CONNECTED*Household thinks government should } \\
\text { give connection subsidy to low-income households } \\
\text { for improved water supply services }\end{array}$ & 0.12 & -0.353 & 0.016 \\
\hline POOR*Monthly consumption charge & 101 & -0.001 & 0.053 \\
\hline POOR ${ }^{*}$ One time connection fee & 1312 & & \\
\hline POOR ${ }^{*}$ Household receives remittance & 0.02 & 0.697 & 0.025 \\
\hline $\begin{array}{l}\text { POOR }^{* \%} \text { households think water quality of their } \\
\text { alternative sources is excellent or good in GN }\end{array}$ & 0.12 & 0.426 & 0.101 \\
\hline $\begin{array}{l}\text { POOR }^{*} \text { Household is particularly conscious of } \\
\text { institutional issues }\end{array}$ & 0.005 & 1.035 & 0.095 \\
\hline $\begin{array}{l}\text { POOR }{ }^{*} \text { Household has experienced a case of } \\
\text { morbidity event }\end{array}$ & 0.01 & -1.081 & 0.072 \\
\hline NEGOMBO*Monthly consumption charge & 218 & & \\
\hline NEGOMBO* One time connection fee & 2939 & & \\
\hline NEGOMBO*Household receives remittance & 0.04 & -0.279 & 0.227 \\
\hline NEGOMBO*Distance to road & 0.17 & -0.229 & 0.130 \\
\hline $\begin{array}{l}\text { NEGOMBO*\% households think water quality of } \\
\text { their alternative sources is excellent or good in GN }\end{array}$ & 0.25 & -0.346 & 0.113 \\
\hline $\begin{array}{l}\text { NEGOMBO*Private sector will provide improved } \\
\text { service }\end{array}$ & 0.25 & 0.268 & 0.053 \\
\hline Number of observations & & 1735 & \\
\hline Likelihood Ratio Statistic & & 439 & 0.000 \\
\hline Pseudo $\mathrm{R}^{2}$ & & 0.19 & \\
\hline$\%$ Responses that are correctly predicted & & 74 & \\
\hline Log likelihood & & -917 & \\
\hline
\end{tabular}


Table 4. Proportion of Sample Households $(\mathrm{N}=1818)$ in Each Sub-Group Category

\begin{tabular}{|c|c|c|}
\hline District & Poor & Nonpoor \\
\hline Gampaha (Greater Negombo) & & \\
\hline Connected & $2 \%$ & $9 \%$ \\
\hline Unconnected & $5 \%$ & $28 \%$ \\
\hline Kalutara - Galle & & \\
\hline Connected & $4 \%$ & $22 \%$ \\
\hline Unconnected & $9 \%$ & $20 \%$ \\
\hline
\end{tabular}


Table 5. Summary of Uptake Estimates by Sub-Group with Public Sector Provision: Regression Model Predictions*

\begin{tabular}{|c|c|c|}
\hline District & Poor & Nonpoor \\
\hline Gampaha (Greater Negombo) & & \\
\hline Connected & $47 \%$ & $63 \%$ \\
\hline Unconnected & $30 \%$ & $45 \%$ \\
\hline Kalutara - Galle & & \\
\hline Connected & $53 \%$ & $68 \%$ \\
\hline Unconnected & $35 \%$ & $51 \%$ \\
\hline
\end{tabular}

* For this set of simulations, we use the regression model reported in Table 3 and set the private provision dummy equal to 0 , monthly charge at Rs. 200, and connection cost at Rs. 0 and 9,000 for the connected and unconnected households, respectively. The text describes the purpose, method and outcome of this simulation. 
Table 6. Summary of Uptake Estimates by Sub-Group with Private Sector Provision: Regression Model Predictions*

\begin{tabular}{|c|c|c|}
\hline District & Poor & Nonpoor \\
\hline Gampaha (Greater Negombo) & & \\
\hline Connected & $49 \%$ & $64 \%$ \\
\hline Unconnected & $32 \%$ & $47 \%$ \\
\hline Kalutara - Galle & & \\
\hline Connected & $44 \%$ & $59 \%$ \\
\hline Unconnected & $27 \%$ & $42 \%$ \\
\hline
\end{tabular}

* For this set of simulations, we use the regression model reported in Table 3 and set the private provision dummy equal to 1 , monthly charge at Rs. 200, and connection cost at Rs. 0 and 9,000 for the connected and unconnected households, respectively. The text describes the purpose, method and outcome of this simulation. 
Table 7. Summary of Uptake Estimates by Sub-Group with Public Sector Provision and Free Provision for Poor Households: Regression Model Predictions*

\begin{tabular}{|c|c|c|}
\hline District & Poor & Nonpoor \\
\hline Gampaha (Greater Negombo) & & \\
\hline Connected & $67 \%$ & $63 \%$ \\
\hline Unconnected & $70 \%$ & $45 \%$ \\
\hline Kalutara - Galle & & \\
\hline Connected & $72 \%$ & $68 \%$ \\
\hline Unconnected & $74 \%$ & $51 \%$ \\
\hline
\end{tabular}

* For this set of simulations, we use the regression model reported in Table 3 and set the private provision dummy equal to 0 , free connection fee and monthly charge for the poor households, and Rs. 200 consumption charge for the nonpoor households. For the nonpoor unconnected households, a connection cost of Rs. 9,000 is applied. The text describes the purpose, method and outcome of this simulation. 